European

Thyroid Journal
Eur Thyroid J 2019;8:31-40

DOI: $10.1159 / 000493977$
Received: June 7, 2018

Accepted after revision: September 21, 2018

Published online: November 8, 2018

\title{
Trends in Diagnostics, Surgical Treatment, and Prognostic Factors for Outcomes in Medullary Thyroid Carcinoma in Norway: A Nationwide Population-Based Study
}

\author{
Else Marie Opsahla, b Lars Andreas Akslen ${ }^{c, d} \quad$ Ellen Schlichting $^{a}$ Turid Aas ${ }^{\mathrm{e}}$ \\ Katrin Brauckhoffe Anne Irene Hagen ${ }^{f} \quad$ Alf Frimann Rosenlund $^{g}$ Eva Sigstad ${ }^{\text {h }}$

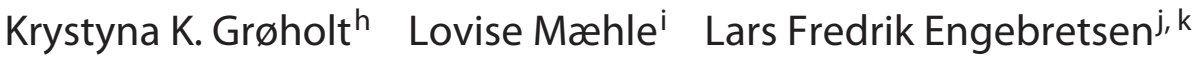 \\ Lars H. Jørgensen' Jan Erik Varhaug ${ }^{m}$ Trine Bjørob, n \\ a Section of Breast and Endocrine Surgery, Department of Oncology, Oslo University Hospital, Oslo, Norway;

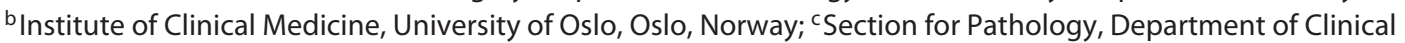 \\ Medicine, Centre for Cancer Biomarkers CCBIO, University of Bergen, Bergen, Norway; ${ }^{d}$ Department of Pathology,

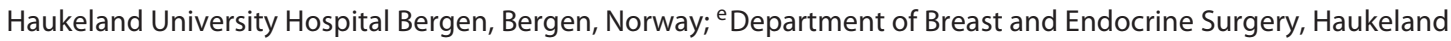 \\ University Hospital, Bergen, Norway; ${ }^{f}$ Department of Breast and Endocrine Surgery, St. Olavs University Hospital, \\ Trondheim, Norway; ${ }^{9}$ Section of Breast and Endocrine Surgery, Department of Surgery, University Hospital of \\ North Norway, Tromsø, Norway; ${ }^{\text {h}}$ Department of Pathology, Oslo University Hospital, Oslo, Norway; ${ }^{\text {Department }}$ \\ of Medical Genetics, Oslo University Hospital, Oslo, Norway; ${ }^{j}$ Center for Medical Genetics and Molecular Medicine, \\ Haukeland University Hospital, Bergen, Norway; ${ }^{k}$ Department of Medical Genetics, St. Olavs University Hospital, \\ Trondheim, Norway; 'Department of Thoracic Surgery, Oslo University Hospital, Oslo, Norway; m Department of \\ Clinical Science, University of Bergen, Bergen, Norway; ${ }^{\text {n}}$ Department of Medical Biochemistry, Oslo University \\ Hospital, Oslo, Norway
}

\section{Keywords}

Medullary thyroid carcinoma · Trends · Diagnostics · Surgery $\cdot$ Pathology $\cdot$ Outcome

\begin{abstract}
Background: Medullary thyroid carcinoma (MTC) is rare. Nationwide population-based studies are important to evaluate its clinical course. Objectives: To describe all patients with MTC in Norway during 1994-2016 and compare timerelated trends in diagnostics and surgical treatment, including prognostic factors for biochemical cure and diseasespecific survival (DSS). Methods: This retrospective popula-
\end{abstract}

tion-based cohort study includes data for 228 out of 237 patients (96\%) with MTC; 201 patients were surgically treated. Patients were identified in the 4 regional centers treating MTC and by the Cancer Registry of Norway. Data were collected from patients' files. Trends were compared over 2 study periods. Results: MTC accounted for $4.2 \%$ of thyroid carcinomas. During the study periods, the incidence increased from 0.18 to $0.25: 100,000$ per year, preoperative diagnostics improved with increased use of calcitonin, ultrasound, and fine-needle cytology $(p=0.010, p<0,001$, and

Jan Erik Varhaug died on December 14, 2017.

\section{KARGER}

E-Mail karger@karger.com www.karger.com/etj
(C) 2018 European Thyroid Association

Published by S. Karger AG, Basel
Else Marie Opsahl, MD

Section for Breast and Endocrine Surgery, Department of Oncology Oslo University Hospita, PO Box 4950 Nydalen NO-0424 Oslo (Norway)

E-Mail e.m.opsahl@medisin.uio.no 
$p=0.001)$, patients were diagnosed at an earlier tumor stage $(p=0.004)$, and more patients were cured $(p=0.002)$. Via multivariate analysis of patients with metastatic lymph nodes, independent prognostic factors for cure were: a low ratio of metastatic and total number of dissected lymph nodes $(p=0.021)$ and no extrathyroidal extension ( $p=$ 0.030 ). Independent prognostic factors for DSS were: no distant metastasis, a younger age, and a low ratio of metastatic and dissected lymph nodes $(p=0.005, p=0.020, p=$ 0.022). Conclusions: Preoperative diagnostics have improved over time with increased therapeutic control. A low ratio of metastatic and dissected lymph nodes predicts better outcomes in patients with metastatic lymph nodes.

(c) 2018 European Thyroid Association Published by S. Karger AG, Basel

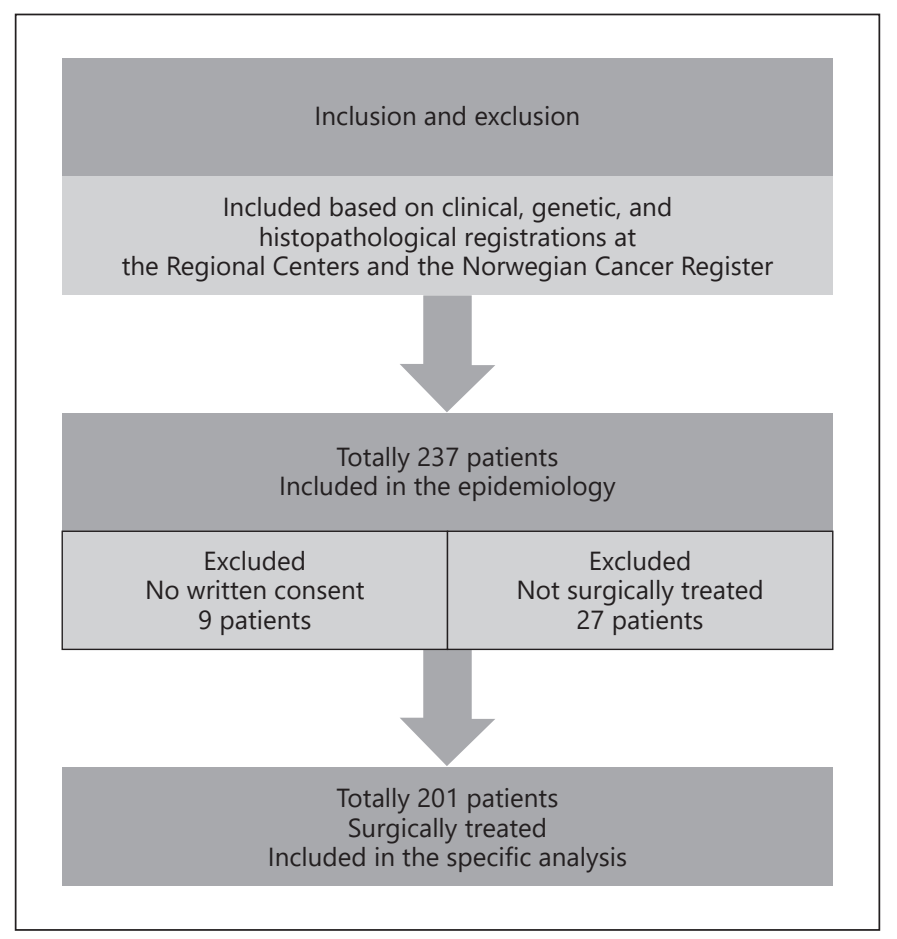

Fig. 1. Study cohort with inclusion and exclusion flow chart. MTC occurs sporadically in $75 \%$ of the patients. In $25 \%$ of the patients, MTC is hereditary and a part of multiple endocrine neoplasia type 2A (MEN2A) (90-95\%) and type 2B (MEN2B) (5-10\%), autosomal dominant syndromes caused by a germline mutation in the REarranged during Transfection (RET) proto-oncogene [1,4-8].

Major studies have shown that age at the time of diagnosis and tumor stage are the most important prognostic factors regarding cure and survival, with reported 5- and 10-year disease specific survival (DSS) rates of 76-99 and 70-87\% [1, 9-15].

During the last decades, preoperative diagnostics have improved due to better sensitivity and increased use of biochemical, radiological, and cytological examinations, hence making MTC diagnosis possible at lower tumor stages $[3,12,13]$. Calcitonin is a good tumor marker in diagnostics and follow-up.

Surgery is the only means of potential cure for MTC. To obtain a biochemical cure, it should be performed at an early stage of the disease and to a sufficient extent [3, $4,16,17]$.

In Norway, the handling of MTC is regionalized and since 1953 it has been mandatory that all cancer diagnostics as well as treatment be reported to the Cancer Registry of Norway, allowing population-based cohort studies. Studies of hereditary MTC in Norway from overlapping time periods but with different objectives have been reported earlier $[18,19]$. The present study aims to describe all patients with MTC (both sporadic and hereditary) in
Norway from 1994 to 2016 and compare time-related trends in diagnostics and surgical treatment, including prognostic factors for biochemical cure and DSS.

\section{Materials and Methods}

This nationwide, population-based retrospective cohort study covers all patients with sporadic and hereditary MTC initially found in clinical, genetic, and histopathological registrations in the 4 regional centers treating MTC during 1994-2016, as well as all patients registered with MTC in the Cancer Registry of Norway during the same time period. Figure 1 presents a flow chart of inclusion and exclusion. Surgical treatment was not performed in 27 patients due to locally advanced or disseminated disease, other advanced diseases, or old age in 22 patients. In 5 patients, MTC was diagnosed by autopsy. Those patients were excluded from this study.

This study used data from the Cancer Registry of Norway. The interpretation and reporting of these data are the sole responsibility of the authors, and no endorsement by the Cancer Registry of Norway is intended or should be inferred.

Data was collected from patient files. The censoring date for follow-up data was March 1, 2017. To evaluate changes in diagnostics and treatment of MTC, this study covers 2 time periods, i.e., 1994 to June 2005 and July 2005 to 2016.

Completed primary surgery was in this study defined as one or more surgical procedures within the first year. Regular follow-up included calcitonin analysis and ultrasound of the neck. Radio-
Opsahl et al. 
logical and nuclear medical examinations were performed upon indication. Follow-up was generally performed early postoperatively, every 3-6 months in the first postoperative year, and then once a year. However, the frequencies have varied depending on the patients' biochemical and clinical status. Biochemical cure was evaluated after completed primary surgery. The lowest measured calcitonin value after completed primary surgery and before known disease progression and recurrent treatment was used to evaluate biochemical cure.

\section{Biochemical, Genetic, and Histopathological Analysis}

Calcitonin was analyzed by routine immunoassay in 2 laboratories, i.e., Oslo University Hospital (OUH) (Oslo, Norway) and Haukeland University Hospital (HUH) (Bergen, Norway). The assays, especially the limits of detection which varied from $<2.0$ to $<$ $1.0 \mathrm{pmol} / \mathrm{L}$ before 2003, have changed over time. From $2003 \mathrm{calci}-$ tonin was analyzed using Immulite ${ }^{\circledR}$ (Siemens), with detection limits varying from $<1.5$ to $<1.0 \mathrm{pmol} / \mathrm{L}$; from 2007 the detection limit was $<0.6 \mathrm{pmol} / \mathrm{L}$, and from 2015 it was analyzed at OUH using Roche $\operatorname{COBAS}^{\circledR}$ Module E, with a limit of detection $<0.3$ $\mathrm{pmol} / \mathrm{L}$. After total thyroidectomy, biochemical cure was defined as no calcitonin detected with the assay used, and after lobectomy it was defined as calcitonin within reference values at $\mathrm{OUH}<2.1$ and $<3.1 \mathrm{pmol} / \mathrm{L}$ and at $\mathrm{HUH}<1.6$ and $<2.2 \mathrm{pmol} / \mathrm{L}$ in females and males, respectively. In the present study, $3.0 \mathrm{pmol} / \mathrm{L}$ was used as the cutoff value for both sexes.

RET mutation analysis followed international standards, using reference sequences NM_020975.3 and NM_020975.4.

MTC tumor stage was classified according to the American Joint Committee of Cancer tumor-node-metastasis (TNM) classification, 7th edition (UICC 2010), the current classification during data collection [20]. At the primary surgery, pTNM was defined as the total pTNM after the primary surgery. When indicating the MTC tumor stage, an unknown preoperative metastatic status $(\mathrm{Mx})$ and no lymph node dissection $(\mathrm{Nx})$ were interpreted as no metastasis (M0) and no metastatic lymph nodes (pN0) in the patients who achieved biochemical cure after the primary surgery.

\section{Statistics}

Data were analyzed using SPSS software (SPSS for Windows, version 25). For continuous variables not following normal distribution, a non-parametric test for independent samples (MannWhitney U test) was used. Group differences and associations between categorical variables were analyzed using the Pearson $\chi^{2}$ two-sided test. Prognostic factors for postoperative biochemical cure were explored by univariate analysis and by multivariate analysis using logistic regression. DSS were analyzed via Kaplan-Meier survival analysis, with the log-rank test applied to explore differences in univariate analyses. For multivariate survival analysis, proportional hazards regression analysis (Cox) was applied, with the Omnibus test as an lratio (likelihood ratio) test for differences. $p<0.05$ was considered statistically significant.

\section{Study Approval}

The Regional Committee for Medical and Health Research Ethics (REC) of Western Norway approved this study. All of the patients included, or their parents if the patients were children, gave written informed consent. Furthermore, REC granted permission to include deceased patients.

Trends in Diagnostics and Treatment of MTC in Norway

\section{Results}

\section{Epidemiology}

During 1994-2016, the Cancer Registry of Norway recorded 5,610 patients with primary thyroid carcinoma [21], among these, MTC accounted for $4.2 \%$ (237 patients) of the cases. The average population in Norway per year in the first and second study period counted 4,461,741 and 4,897,386 citizens, respectively [22]. Annually, an average of 10.3 patients were diagnosed with MTC, i.e., 8.2 patients (of a total of 94) and 12.4 patients (of a total of 143) in the first and second period, respectively. The average incidence rate was 0.22 per 100,000 person years (1:456,964 persons per year). It increased from $0.18: 100,000$ in the first period to $0.25: 100,000$ in the second.

Of all of the MTC patients, the RET mutation was found in 37 patients (18\%); 32 patients $(86 \%)$ were ME$\mathrm{N} 2 \mathrm{~A}$ and $5(14 \%)$ were MEN2B. On the censoring date, RET mutation analysis was not performed in 44 surgically treated patients (22\%).

\section{Clinical and Histopathological Characteristics}

Table 1 presents the characteristics of the 201 surgically treated patients in this study. Division into 2 study periods enabled the evaluation of time-related trends in diagnostics and treatment of MTC. Compared to the first period, the second period displayed a significant increase in the use of preoperative diagnostics as follows: calcitonin, 73 versus $55 \%(p=0.010)$, ultrasound of the neck, 99 versus $60 \%$ $(p<0.001)$, and fine-needle cytology, 91 versus $74 \%$ of the patients $(p=0.001)$. The patients were diagnosed at an earlier tumor stage, with tumor stage IV in 35.5 versus $61 \%$ of the patients $(p=0.004)$, and more patients achieved biochemical cure (i.e., 58 vs. $35 \%, p=0.002$ ).

Lobectomy was performed in 26 (13\%) of the surgically treated patients (Table 1); in 9 patients, due to palliative surgery, old age, and no contralateral disease at imaging and paresis of the recurrent laryngeal nerve, and in 17 patients, lobectomy was considered sufficient thyroid surgery. Of the 26 patients, 14 had lymph node dissection in the ipsilateral central neck, 5 had lymph node dissection in the ipsilateral lateral neck, and 1 had lymph dissection in the bilateral lateral neck. In 11 patients, no lymph node dissection was performed. Tumor stages I, II, and IV and an unknown stage was found in 9, 7, 7, and 3 patients, respectively. After a median follow-up of 22 months (range 1-124), 13 patients were biochemically cured, 4 had biochemical disease without structural disease on imaging, 2 had clinical disease, and 7 had died, including 4 due to MTC. 
Table 1. Trends in clinical and histopathological data in 201 surgically treated patients with MTC divided into 2 study periods

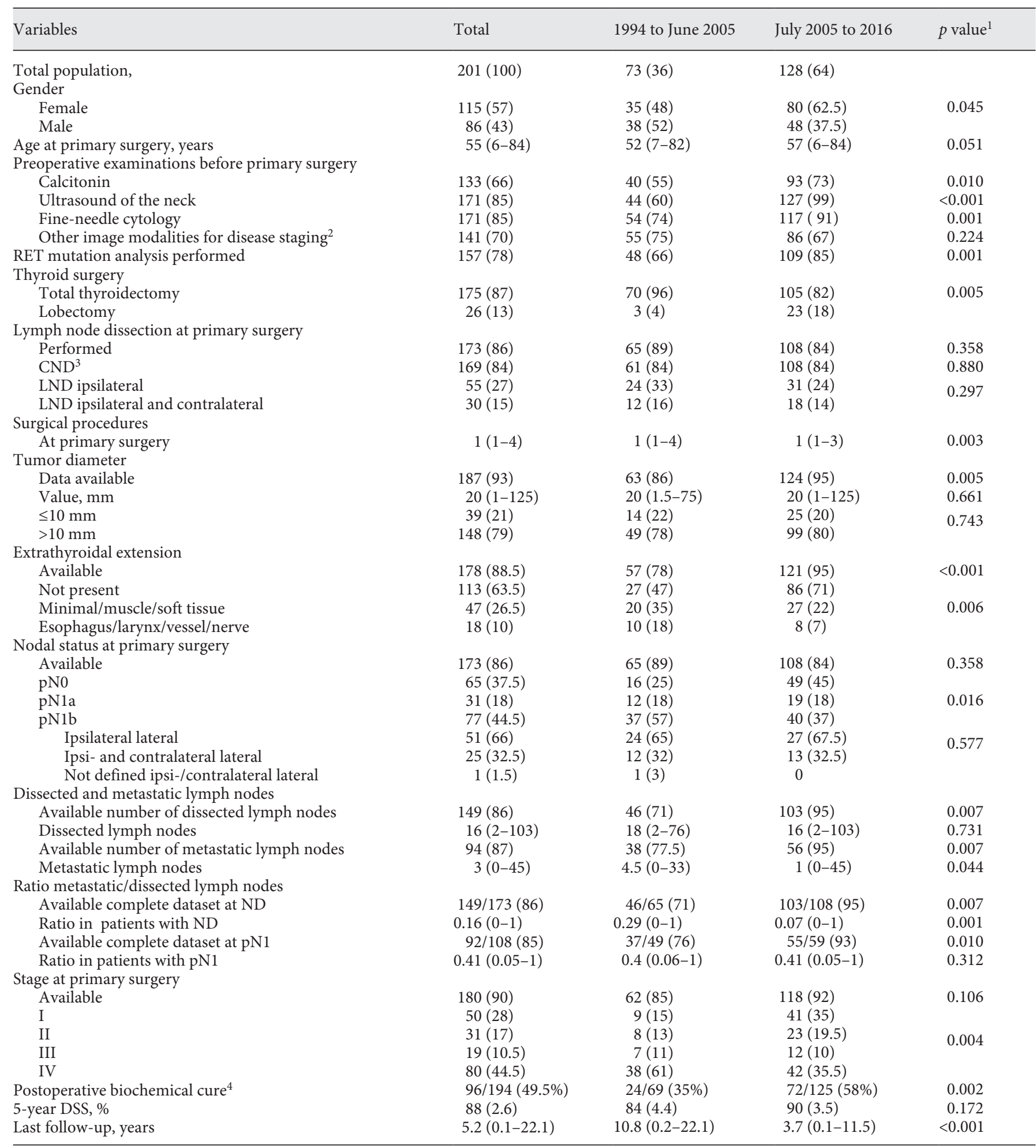

Values are presented as numbers (\%), means \pm SE, or medians (range) unless otherwise stated. TT, total thyroidectomy; CND, central lymph node dissection in the neck; LND, lateral lymph node dissection in the neck; ND, lymph node dissection; pN1, metastatic lymph nodes. ${ }^{1}$ Only patients with available data were included in the analysis. ${ }^{2}$ Includes CT, MRI, PET, scintigraphy, ultrasound of the liver, and chest X-ray. ${ }^{3}$ Unilateral CND in 8 patients in the first period and 17 patients in the second period. ${ }^{4}$ Available information in $69(95 \%)$ and 125 (98\%) patients in the first and second periods, respectively. 
Table 2. Postoperative biochemical cure after completed primary surgery

\begin{tabular}{|c|c|c|c|}
\hline Variables & Cured $^{1,2}, n(\%)$ & Not cured, $n(\%)$ & $p$ value \\
\hline Total population, $n$ & $96(49)$ & $98(51)$ & \\
\hline \multicolumn{4}{|l|}{ Gender } \\
\hline Female & $63(66)$ & $48(49)$ & \multirow{2}{*}{0.019} \\
\hline Male & $33(34)$ & $50(51)$ & \\
\hline \multicolumn{4}{|l|}{ Age, years } \\
\hline Median (range) & $53.5(6-82)$ & $58.5(8-83)$ & 0.426 \\
\hline$<45$ years & $28(29)$ & $33(34)$ & \multirow{2}{*}{0.499} \\
\hline$\geq 45$ years & $68(71)$ & $65(66)$ & \\
\hline \multicolumn{4}{|l|}{ Preoperative examinations before primary surgery } \\
\hline Calcitonin & $55(57)$ & $75(77)$ & 0.004 \\
\hline Ultrasound of the neck & $90(94)$ & $77(79)$ & 0.002 \\
\hline Fine-needle cytology & $80(83)$ & $86(88)$ & 0.381 \\
\hline \multicolumn{4}{|l|}{ Year of surgery } \\
\hline 1994 to June 2005 & $24(25)$ & $45(46)$ & \multirow{2}{*}{0.002} \\
\hline July 2005 to 2016 & $72(75)$ & $53(54)$ & \\
\hline \multicolumn{4}{|l|}{ Primary surgery in the neck } \\
\hline Lobectomy \pm ipsilateral $\mathrm{CND} / \mathrm{LND}^{3}$ & $16(17)$ & $8(8)$ & \multirow{4}{*}{$<0.001$} \\
\hline TT & $13(13.5)$ & $3(3)$ & \\
\hline $\mathrm{TT}+\mathrm{CND}^{4}$ & $54(56)$ & $23(23.5)$ & \\
\hline $\mathrm{TT}+\mathrm{CND}+\mathrm{LND}^{5}$ & $13(13.5)$ & $64(65.5)$ & \\
\hline \multicolumn{4}{|l|}{ Surgical procedures at primary surgery } \\
\hline 1 & $77(80)$ & $55(56)$ & \multirow[t]{2}{*}{$<0.001$} \\
\hline$\geq 2$ & $19(20)$ & $43(44)$ & \\
\hline Tumor diameter $(n=181)$ & 92 & 89 & \\
\hline Value, $\mathrm{mm}$ & $17.5(1-67)$ & $25(2-125)$ & $<0.001$ \\
\hline$\leq 10 \mathrm{~mm}$ & $28(30)$ & $11(12)$ & \multirow{2}{*}{0.003} \\
\hline$>10 \mathrm{~mm}$ & $64(70)$ & $78(88)$ & \\
\hline Extrathyroidal extension $(n=173)$ & 84 & 89 & \multirow{4}{*}{$<0.001$} \\
\hline Not present & $80(95)$ & $31(35)$ & \\
\hline Minimal/muscle/soft tissue & $4(5)$ & $40(45)$ & \\
\hline Esophagus/larynx/vessel/nerve & 0 & $18(20)$ & \\
\hline Nodal status at primary surgery $(n=168)$ & 73 & 95 & \multirow{4}{*}{$<0.001$} \\
\hline pNo & $54(74)$ & $8(8)$ & \\
\hline pN1a & $12(16)$ & $18(19)$ & \\
\hline pN1b & $7(10)^{6}$ & $69(73)$ & \\
\hline Metastatic dissected lymph nodes at pN1 $(n=91)$ & 18 & 73 & \\
\hline Metastatic lymph nodes & $3.5(1-13)$ & $10(1-45)$ & $<0.001$ \\
\hline Dissected lymph nodes & $19(8-49)$ & $26(2-103)$ & 0.113 \\
\hline Ratio metastatic/dissected lymph nodes $(n=91)$ & 18 & 73 & \multirow{3}{*}{$<0.001$} \\
\hline In patients with $\mathrm{pN} 1$ & $0.19(0.05-0.63)$ & $0.43(0.05-1)$ & \\
\hline Stage $(n=177)$ & 96 & 81 & \\
\hline I & $46(48)$ & $2(2.5)$ & \multirow{4}{*}{$<0.001$} \\
\hline II & $31(32)$ & 0 & \\
\hline III & $12(12.5)$ & $7(8.5)$ & \\
\hline IV & $7(7.5)$ & $72(89)$ & \\
\hline Calcitonin analyzed after completed primary $(n=193)$ & 96 & 97 & \multirow[t]{2}{*}{0.094} \\
\hline Surgery, months & $3(0.03-184)$ & $2.1(0.03-98)$ & \\
\hline
\end{tabular}

Values are presented as numbers (\%) or medians (range). Information was available for 194 of 201 surgically treated MTC patients, and postoperative calcitonin was analysed in 193 patients. In 1 patient calcitonin was not measured, but the patient had persistent clinical disease and was not cured. Only patients with available data were included in the univariate analysis. TT, total thyroidectomy; CND, central lymph node dissection in the neck; LND, lateral lymph node dissection in the neck; pN1, metastatic lymph nodes. ${ }^{1}$ Postoperative biochemical cure was defined as a basal calcitonin below the limit of detection after total thyroidectomy and basal calcitonin within the normal range when lobectomy alone was performed. ${ }^{2}$ One patient with total thyroidectomy and tumour stage pT2N0 had postoperative calcitonin $0.4 \mathrm{pg} / \mathrm{mL}$, and the patient was categorized as cured. ${ }^{3}$ CND was ipsilateral in 13 patients, and LND was ipsilateral in 5 patients and ipsi-and contralateral in 1 patient. ${ }^{4}$ Ipsilateral in 2 and 6 patients in the cured and not cured groups, respectively. ${ }^{5} \mathrm{CND}$ was not performed in 1 and 3 patients in the cured and not cured groups, respectively. ${ }^{6}$ All with ipsilateral lateral lymph node metastasis. 
Fig. 2. DSS by TNM stage IVa+b vs. IVc in MTC in $63(79 \%)$ patients with an available dataset. Stage IVa+b, $n=49$; stage IVc, $n=$ $14(p<0.001)$.

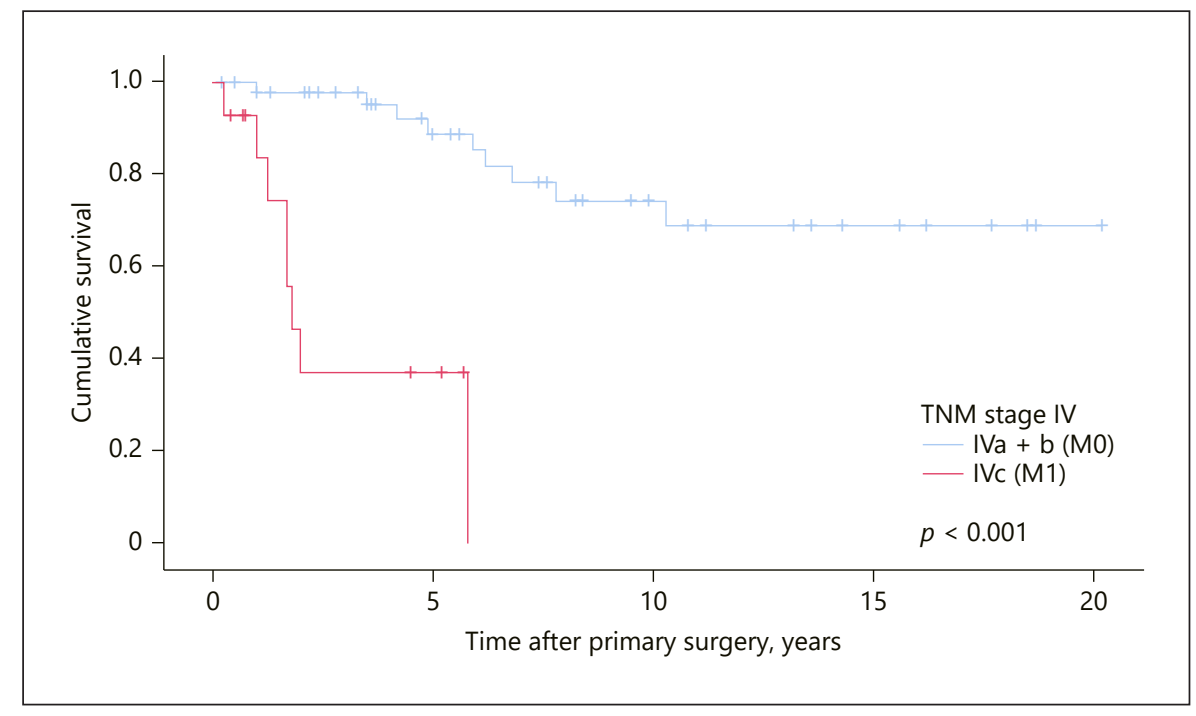

\section{Biochemical Cure Analysis}

Of the 194 patients with available information, 96 (49\%) achieved biochemical cure. Prognostic factors for biochemical cure were analyzed by univariate analysis, and multivariate logistic regression models were created to evaluate prognostic factors in patients with metastatic lymph nodes among the patients with available datasets (Tables 2, 3). The relation between metastatic lymph nodes and the total number of dissected lymph nodes was, by univariate analysis, also evaluated in the patients with metastatic lymph nodes only. It was significantly lower in the cured patients compared to the not cured patients $(p<0.001)$. In the adjusted multivariate analysis, independent prognostic factors for biochemical cure were found to be a low ratio of metastatic and dissected lymph nodes ( $p=0.021)$ prior to the absence of extrathyroidal extension $(p=0.030)$, with corresponding low OR for not achieving biochemical cure in these patients (OR 0.008 and OR 0.151; Table 3).

\section{Survival Analysis}

After a median postoperative follow-up of 5.2 years (range $0.1-22.1$ ), 27 patients (13.5\%) died due to MTC, 25 patients had tumor stage IV, and 2 patients had an unknown tumour stage. The 5- and 10-year DSS was 88 and $82 \%$, respectively. The 5 -year DSS improved during the 2 study periods from 84 to $90 \%$. The difference was not significant ( $p=0.172$ ), but the postoperative follow-up was shorter (Table 1). Eighty patients had tumor stage IV; 49 (61\%) patients had stage IVa+b (M0) and 14 patients (18\%) had stage IVc (M1), with a significant difference in
5 -year DSS between the 2 groups ( 89 vs $37 \%, p<0.001$; Fig. 2). In 17 patients (21\%) with $\mathrm{Mx}$, it was impossible to differentiate between stage IVa+b and stage IVc. A Cox regression model was created to analyze DSS in the patients with metastatic lymph nodes based on available data (Table 4). Independent prognostic factors for DSS were found to be: no distant metastasis $(p=0.005$, HR $206.58)$, a younger age at thyroid surgery $(p=0.020$, HR 1.09 ), and a low ratio of metastatic and dissected lymph nodes $(p=0.022$, HR 2001.61).

\section{Discussion}

Preoperative diagnostics have significantly improved over the last decades. MTC was detected earlier, with a higher proportion of tumor stage I disease, and more patients achieved biochemical cure in the second study period.

This nationwide MTC population study in the molecular RET era covers $96 \%$ of all Norwegian patients treated for MTC from 1994 to 2016. Data collection combined with data from the Cancer Registry of Norway made this population-based study possible and complete with minimal to none selection bias. This adds great strength to this study.

MTC accounted for $4.2 \%$ of thyroid malignancy in Norway. The frequency is in the middle of the $1-10 \%$ reported by older and more recent international studies [ 1 , $3]$, and it is slightly higher compared to the frequency of $3.8 \%$ for 1970-1985 in Norway [2]. The increased inci- 
Table 3. Factors predicting postoperative biochemical cure in 108 patients with metastatic lymph nodes and available data

\begin{tabular}{|c|c|c|c|}
\hline Variable & Patients, $n$ & OR (95\% CI) & $p$ value \\
\hline \multicolumn{4}{|c|}{$\begin{array}{l}\text { Calcitonin before surgery, ultrasound before surgery, surgical procedures at primary surgery, time period, nodal } \\
\text { status, and MLNR }\end{array}$} \\
\hline Total, $n(\%)$ & $91(84)$ & & \\
\hline \multicolumn{4}{|l|}{ Biochemical cure } \\
\hline No vs. yes & 73 vs. 18 & & \\
\hline \multicolumn{4}{|l|}{ Calcitonin analysis before primary surgery } \\
\hline No vs. yes & 16 vs. 75 & $3.289(0.437-24.757)$ & 0.248 \\
\hline \multicolumn{4}{|l|}{ Ultrasound of the neck before primary surgery } \\
\hline No vs. yes & 15 vs. 76 & $4.652(0.406-53.270)$ & 0.216 \\
\hline \multicolumn{4}{|c|}{ Numbers of surgical procedures at primary surgery } \\
\hline 1 vs. $\geq 2$ & 54 vs. 37 & $1.491(0.341-6.514)$ & 0.596 \\
\hline \multicolumn{4}{|l|}{ Time period } \\
\hline 1994 to June 2005 vs. July 2005 to 2016 & 36 vs. 55 & $0.399(0.098-1.622)$ & 0.199 \\
\hline \multicolumn{4}{|l|}{ Nodal status } \\
\hline pN1a vs. pN1b & 27 vs. 64 & $0.184(0.046-0.729)$ & 0.016 \\
\hline \multicolumn{4}{|l|}{ Metastatic/dissected lymph node ratio } \\
\hline Median (range) & $\begin{array}{l}0.19(0.05-0.63) \text { vs. } \\
0.43(0.05-1)\end{array}$ & $0.010(0.000-0.251)$ & 0.005 \\
\hline
\end{tabular}

Extrathyroidal extension, tumor diameter, time period, nodal status, and MLNR

Total, $n(\%) \quad 80(74)$

Biochemical cure

No vs. yes 66 vs. 14

Extrathyroidal extension $\begin{array}{llll}\text { Not present vs. present } & 35 \text { vs. } 45 & 0.080(0.009-0.740) & 0.026\end{array}$

Tumor diameter $\begin{array}{llll}\leq 10 \text { vs. }>10 \mathrm{~mm} & 10 \text { vs. } 70 & 0.716(0.121-4.250) & 0.713\end{array}$

Time period 1994 to June 2005 vs. July 2005 to $2016 \quad 29$ vs. $51 \quad 1.458(0.294-7.226) \quad 0.644$

Nodal status pN1a vs. pN1b

Metastatic/dissected lymph node ratio Median (range)

$\begin{array}{lll}22 \text { vs. } 58 & 0.662(0.146-2.999) & 0.593 \\ & & \\ 0.12(0.05-0.55) \text { vs. } & 0.006(0.000-0.605) & 0.030 \\ 0.43(0.05-1.0) & & \end{array}$

MLNR, extrathyroidal extension, and nodal status

Total, $n(\%)$

Biochemical cure No vs. yes

Metastatic/dissected lymph node ratio Median (range)

Extrathyroidal extension Not present vs. present Nodal status pN1a vs. pN1b $84(78)$

69 vs. 15 $\begin{array}{ll}0.13(0.05-0.55) \text { vs. } & 0.008(0.000-0.488) \\ 0.43(0.05-1.0) & 0.021\end{array}$

35 vs. $49 \quad 0.151(0.027-0.833) \quad 0.030$

22 vs. $62 \quad 0.701(0.166-2.973) \quad 0.630$

In 1 patient postoperative calcitonin was not analysed, but the patient had persistent clinical disease and was not biochemically cured. Logistic regression. 
Table 4. Factors predicting DSS in 108 patients with metastatic lymph nodes and available data

\begin{tabular}{|c|c|c|c|}
\hline Variable & Patients, $n$ & HR (95\% CI) & $p$ value \\
\hline Total number, $n(\%)$ & $65(60)$ & & \\
\hline \multicolumn{4}{|l|}{ Died of MTC } \\
\hline No vs. yes & 54 vs. 11 & & \\
\hline \multicolumn{4}{|l|}{ Time period } \\
\hline 1994 to June 2005 vs. July 2005 to 2016 & 22 vs. 43 & $0.163(0.011-2.370)$ & 0.184 \\
\hline \multicolumn{4}{|l|}{ Age at primary surgery, years } \\
\hline Median (range) & $\begin{array}{c}55.5 \text { (8-82) vs. } \\
60(46-81)\end{array}$ & $1.088(1.014-1.168)$ & 0.020 \\
\hline \multicolumn{4}{|l|}{ Tumor diameter $^{1}$} \\
\hline$\leq 20$ vs. $>20 \mathrm{~mm}$ & 29 vs. 36 & $0.915(0.088-9.510)$ & 0.941 \\
\hline \multicolumn{4}{|l|}{ Extrathyroidal extension } \\
\hline Not present vs. present & 27 vs. 38 & $4.914(0.427-56.581)$ & 0.202 \\
\hline \multicolumn{4}{|l|}{ Nodal status } \\
\hline pN1a vs. pN1b & 16 vs. 49 & $0.963(0.091-10.158)$ & 0.975 \\
\hline \multicolumn{4}{|l|}{ Metastatic/dissected lymph node ratio } \\
\hline Median (range) & $\begin{array}{c}0.31(0.05-0.86) \text { vs. } \\
0.7(0.4-1.0)\end{array}$ & $2,001.607(3.025-1,324,230.237)$ & 0.022 \\
\hline \multicolumn{4}{|l|}{ Metastatic status } \\
\hline M0 vs M1 & 57 vs. 8 & $206.584(5.028-8,487.822)$ & 0.005 \\
\hline
\end{tabular}

Cox regression. ${ }^{1}$ Since none of the patients with a tumour diameter $\leq 10 \mathrm{~mm}$ died of MTC, the variable could not fit the Cox model, and the analyses were performed for tumour diameters $\leq 20 \mathrm{vs} .>20 \mathrm{~mm}$.

dence, i.e., from 0.18 to $0.25: 100,000$ person years, in the first and second study periods is higher than that reported in 1985 by Akslen et al. [2] (i.e., 0.15:100,000 person years). Gatta et al. [10] reported in 2006 a world standardized incidence of 0.13 and a calculated incidence between 0.11 and 0.21 per 100,000 person years.

During the last decades, new diagnostic centers for patients with nodular thyroid disease permit ultrasound of the neck, fine-needle cytology, and biochemical and clinical evaluations by a multidisciplinary team. The result is early diagnosis at a lower tumor stage as well as an increase in incidence. Furthermore, widespread use of ultrasound might be a major causal factor to initiate elucidation of small thyroid nodules. In the present study, ultrasound before surgery was a significant prognostic factor in favor of biochemical cure by univariate analysis (Table 2) but not by multivariate analysis in the selected group of patients with metastatic lymph nodes (Table 3 ). Calcitonin analysis was performed more frequently in the second study period, but it was not a significant prognostic factor in favor of biochemical cure either by univariate or by multivariate analysis (Tables 2,3). Major studies have assessed calcitonin screening at the time of diagnostic evaluation of thyroid nodules. The studies found that MTC was diagnosed at a significantly lower tumor stage with better outcomes when calcitonin was analyzed [23, 24], and it was cost-effective [25]. The national guidelines in Norway do not recommend calcitonin screening in general. However, calcitonin analysis should be considered for patients with thyroid nodules undergoing thyroid surgery [26].

The number of patients who underwent $R E T$ mutation analysis improved significantly in the second study period compared to the first ( 85 vs. $66 \%$ ). It is recommended that $R E T$ mutation analysis be offered to patients with MTC $[3,26]$.

Lobectomy was performed more frequently in the second study period. Patients with MTC diagnosed after lobectomy with normalized calcitonin and a normal neck ultrasound have been monitored consistently with ATA guidelines [3].

Among patients with metastatic lymph nodes, the number of metastatic lymph nodes was significantly higher in patients without biochemical cure compared to the cured patients, but the number of dissected lymph nodes was not. Furthermore, by multivariate analysis the ratio of metastatic and dissected lymph nodes was found to be a significant prognostic factor for both biochemical cure and DSS. This validates the importance of meticulous lymph node dissection to achieve a low ratio in pa-
38

Eur Thyroid J 2019;8:31-40 DOI: $10.1159 / 000493977$
Opsahl et al. 
tients with metastatic lymph nodes. The higher the number of dissected lymph nodes is, the lower the risk of leaving metastatic lymph nodes behind is. This is consistent with other studies emphasizing the importance of systematic and meticulous lymph node dissection in MTC [27-29]. In a population-based but not a nationwide study by Qu et al. [30], a higher ratio was found to predict an inferior survival in MTC. Leggett et al. [31] made the same observation, but not in an analyzed subgroup of patients with lymph node metastasis.

In the present study, the average tumor diameters observed in the 2 periods studied were the same. This is consistent with Torresan et al. [12] and Hirsch et al. [32]. Furthermore, Kazaura et al. [33] concluded that microMTC does not always mean an earlier tumor stage, and that smaller tumors have significant rates of poor prognostic features known to impact the survival of patients. By multivariate analysis, tumor diameter was not found to be significantly prognostic for either biochemical cure or DSS in the present study. Furthermore, significantly less extrathyroidal cancer extension, as well as a higher proportion of tumor stage I and tumor of less than stage IV, was found in the second study period. Extrathyroidal extension was an independent prognostic factor for biochemical cure. These findings both concur with and diverge from previous studies. Machens and Dralle [34] found a significant reduction in the extent of disease and improved biochemical cure with time, while Randle et al. [13] found a significant reduction in tumor diameter and extrathyroidal extension but no reduction in tumor stage over time. In studies by de Groot et al. [9] and Modigliani et al. [11], extrathyroidal extension and stage were found to be the only prognostic factor for biochemical cure.

The present study reports 5- and 10-year DSS of 88 and $82 \%$. This is in line with DSS reported in recent studies $[12,13]$ but higher than those reported by older studies [9-11]. However, the study of Kebebew et al. [1] reported 5 - and 10-year DSS of 89 and $87 \%$, respectively.

There are certain limitations to the present study. The lack of information and missing variables in the first study period may limit this study, including the possibility of stage migration. In the multivariate analysis, the reduced number of patients with complete datasets may constitute a limitation. Furthermore, calcitonin analysis became more precise and sensitive in the second study period. Recent histopathological reports contain more detailed information than earlier reports. Additionally, in recent years, examinations of the specimens have become more extensive to include all nonmetastatic lymph nodes. This may have influenced the ratio of metastatic lymph nodes and total number of dissected lymph nodes. However, the number of dissected lymph nodes did not differ significantly in the 2 periods. Furthermore, the ratio is a composed parameter. This might make the variable difficult to interpret as the ratio increases with increasing numbers of metastatic lymph nodes and decreasing numbers of dissected lymph nodes. However, the higher the number of dissected lymph nodes is, the lower the risk of leaving metastatic lymph nodes behind is, which is still applicable.

In conclusion, better preoperative diagnostics in patients with MTC have improved disease control in Norway. The ratio of metastatic lymph nodes and total number of dissected lymph nodes is an independent prognostic factor for both biochemical cure and DSS. Attention must continue to be paid to systematic compartment-oriented lymph node dissection and it must be further perfected.

\section{Acknowledgement}

We acknowledge Norwegian Radium Hospital Endowments for Research at the OUH for providing research grants to cover travel expenses in connection with the data collection. We also acknowledge Hildegunn Høberg-Vetti, MD (Western Norway Familial Cancer, Center for Medical Genetics and Molecular Medicine, HUH), Kristin Helset, MD (Department of Breast and Endocrine Surgery, St. Olav Hospital, Trondheim University Hospital, Trondheim, Norway), and David Swanson, Statistician (OCBE Advising Service, Oslo Center of Biostatistics and Epidemiology, $\mathrm{OUH})$, for contributing to this study.

\section{Disclosure Statement}

This work was not funded by any organization and it was not supported by any grants. No conflict of interests or competing financial interests exist for any of the authors.

References

Eur Thyroid J 2019;8:31-40

1 Kebebew E, Ituarte PH, Siperstein AE, Duh QY, Clark OH. Medullary thyroid carcinoma: clinical characteristics, treatment, prognostic factors, and a comparison of staging systems. Cancer. 2000 Mar;88(5):1139-48.

2 Akslen LA, Haldorsen T, Thoresen SO, Glattre E. Incidence of thyroid cancer in Norway 1970-1985. Population review on time trend, sex, age, histological type and tumour stage in 2625 cases. APMIS. 1990 Jun;98(6):549-58.

3 Wells SA Jr, Asa SL, Dralle H, Elisei R, Evans DB, Gagel RF, et al.; American Thyroid Association Guidelines Task Force on Medullary Thyroid Carcinoma. Revised American Thyroid Association guidelines for the management of medullary thyroid carcinoma. Thyroid. 2015 Jun;25(6):567-610. 
4 Pelizzo MR, Boschin IM, Bernante P, Toniato A, Piotto A, Pagetta C, et al. Natural history, diagnosis, treatment and outcome of medullary thyroid cancer: 37 years experience on 157 patients. Eur J Surg Oncol. 2007 May; 33(4):493-7.

5 Donis-Keller H, Dou S, Chi D, Carlson KM, Toshima K, Lairmore TC, et al. Mutations in the RET proto-oncogene are associated with MEN 2A and FMTC. Hum Mol Genet. 1993 Jul;2(7):851-6.

6 Mulligan LM, Kwok JB, Healey CS, Elsdon MJ, Eng C, Gardner E, et al. Germ-line mutations of the RET proto-oncogene in multiple endocrine neoplasia type 2A. Nature. 1993 Jun;363(6428):458-60.

7 Eng C, Smith DP, Mulligan LM, Nagai MA, Healey CS, Ponder MA, et al. Point mutation within the tyrosine kinase domain of the RET proto-oncogene in multiple endocrine neoplasia type $2 \mathrm{~B}$ and related sporadic tumours. Hum Mol Genet. 1994 Feb;3(2):237-41.

8 Romei C, Cosci B, Renzini G, Bottici V, Molinaro E, Agate L, et al. RET genetic screening of sporadic medullary thyroid cancer (MTC) allows the preclinical diagnosis of unsuspected gene carriers and the identification of a relevant percentage of hidden familial MTC (FMTC). Clin Endocrinol (Oxf). $2011 \mathrm{Feb}$; 74(2):241-7.

9 de Groot JW, Plukker JT, Wolffenbuttel BH, Wiggers T, Sluiter WJ, Links TP. Determinants of life expectancy in medullary thyroid cancer: age does not matter. Clin Endocrinol (Oxf). 2006 Dec;65(6):729-36.

10 Gatta G, Ciccolallo L, Kunkler I, Capocaccia R, Berrino F, Coleman MP, et al.; EUROCARE Working Group. Survival from rare cancer in adults: a population-based study. Lancet Oncol. 2006 Feb;7(2):132-40.

11 Modigliani E, Cohen R, Campos JM, ConteDevolx B, Maes B, Boneu A, et al. Prognostic factors for survival and for biochemical cure in medullary thyroid carcinoma: results in 899 patients. The GETC Study Group. Groupe d'étude des tumeurs à calcitonine. Clin Endocrinol (Oxf). 1998 Mar;48(3):265-73.

12 Torresan F, Cavedon E, Mian C, Iacobone M. Long-Term Outcome After Surgery for Medullary Thyroid Carcinoma: A Single-Center Experience. World J Surg. 2018 Feb;42(2): $367-75$.
13 Randle RW, Balentine CJ, Leverson GE, Havlena JA, Sippel RS, Schneider DF, et al. Trends in the presentation, treatment, and survival of patients with medullary thyroid cancer over the past 30 years. Surgery. 2017 Jan;161(1): $137-46$.

14 Machens A, Dralle H. Breach of the thyroid capsule and lymph node capsule in node-positive papillary and medullary thyroid cancer: different biology. Eur J Surg Oncol. 2015 Jun; 41(6):766-72.

15 Roman S, Lin R, Sosa JA. Prognosis of medullary thyroid carcinoma: demographic, clinical, and pathologic predictors of survival in 1252 cases. Cancer. 2006 Nov; 107(9):213442.

16 Machens A, Dralle H. Biomarker-based risk stratification for previously untreated medullary thyroid cancer. J Clin Endocrinol Metab. 2010 Jun;95(6):2655-63.

17 Dralle H, Machens A. Surgical management of the lateral neck compartment for metastatic thyroid cancer. Curr Opin Oncol. 2013 Jan; 25(1):20-6.

18 Brauckhoff M, Machens A, Lorenz K, Bjøro T, Varhaug JE, Dralle H. Surgical curability of medullary thyroid cancer in multiple endocrine neoplasia 2B: a changing perspective. Ann Surg. 2014 Apr;259(4):800-6.

19 Opsahl EM, Brauckhoff M, Schlichting E, Helset K, Svartberg J, Brauckhoff K, et al. A Nationwide Study of Multiple Endocrine Neoplasia Type 2A in Norway: Predictive and Prognostic Factors for the Clinical Course of Medullary Thyroid Carcinoma. Thyroid. 2016 Sep;26(9):1225-38.

20 Edge SB, Byrd DR, Compton CC, Fritz AG, Greene FL, Trotti A, editors. AJCC Cancer Staging Manual. 7th ed. New York (NY): Springer-Verlag; 2010.

21 Cancer Registry of Norway. Available at: www.kreftregisteret.no. Accessed January 31, 2018.

22 Statistic Norway. Available at: www.ssb.no. Accessed April 25, 2017.

23 Elisei R, Bottici V, Luchetti F, Di Coscio G, Romei C, Grasso L, et al. Impact of routine measurement of serum calcitonin on the diagnosis and outcome of medullary thyroid cancer: experience in 10,864 patients with nodular thyroid disorders. J Clin Endocrinol Metab. 2004 Jan;89(1):163-8.
24 Costante G, Meringolo D, Durante C, Bianchi $D$, Nocera M, Tumino S, et al. Predictive value of serum calcitonin levels for preoperative diagnosis of medullary thyroid carcinoma in a cohort of 5817 consecutive patients with thyroid nodules. J Clin Endocrinol Metab. 2007 Feb;92(2):450-5.

25 Cheung K, Roman SA, Wang TS, Walker HD, Sosa JA. Calcitonin measurement in the evaluation of thyroid nodules in the United States: a cost-effectiveness and decision analysis. J Clin Endocrinol Metab. 2008 Jun;93(6):217380.

26 National Guidelines in Norway 29th of June 2017 (In Norwegian). Available at www. Helsedirektoratet.no. Accessed August 23, 2018.

27 Dralle H, Damm I, Scheumann GF, Kotzerke J, Kupsch E, Geerlings H, et al. Compartmentoriented microdissection of regional lymph nodes in medullary thyroid carcinoma. Surg Today. 1994;24(2):112-21.

28 Moley JF, Wells SA, Dilley WG, Tisell LE. Reoperation for recurrent or persistent medullary thyroid cancer. Surgery. 1993 Dec;114(6): 1090-5.

29 Tisell LE, Hansson G, Jansson S, Salander H. Reoperation in the treatment of asymptomatic metastasizing medullary thyroid carcinoma. Surgery. 1986 Jan;99(1):60-6.

30 Qu N, Shi RL, Lu ZW, Liao T, Wen D, Sun $\mathrm{GH}$, et al. Metastatic lymph node ratio can further stratify risk for mortality in medullary thyroid cancer patients: A population-based analysis. Oncotarget. 2016 Oct; 7(40):6593745.

31 Leggett MD, Chen SL, Schneider PD, Martinez SR. Prognostic value of lymph node yield and metastatic lymph node ratio in medullary thyroid carcinoma. Ann Surg Oncol. 2008 Sep;15(9):2493-9.

32 Hirsch D, Twito O, Levy S, Bachar G, Robenshtok E, Gross DJ, et al. Temporal Trends in the Presentation, Treatment, and Outcome of Medullary Thyroid Carcinoma: An Israeli Multicenter Study. Thyroid. 2018 Mar;28(3): 369-76.

33 Kazaure HS, Roman SA, Sosa JA. Medullary thyroid microcarcinoma: a population-level analysis of 310 patients. Cancer. 2012 Feb; 118(3):620-7.

34 Machens A, Dralle H. Surgical cure rates of sporadic medullary thyroid cancer in the era of calcitonin screening. Eur J Endocrinol. 2016 Sep;175(3):219-28. 